Reseñas

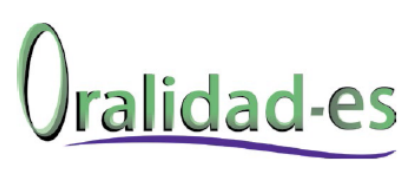

REVISTA DE LA RED

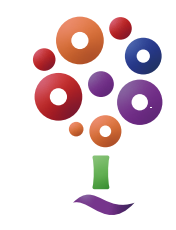

\title{
Reseña del libro Prácticas dialógicas en la escuela. Asamblea de aula, exposición oral y conversación académica
}

\author{
Review of the book Dialogical practices in school. \\ Classroom assembly, oral presentation and academic \\ conversation
}

Cecilia Villabona

cevilla48@hotmail.com

Grupo de Lenguaje Bacatá. Red Colombiana y

Latinoamericana de Lenguaje, Colombia

Villabona, C. (2017). Reseña del libro Prácticas dialógicas en la escuela. Asamblea de aula, exposición oral y conversación académica. Oralidad-es, 3(6), 53-56. https://revistaoralidad-es.com/index.php/ro-es/article/view/87/62

Fecha de recepción: 20 de octubre de 2017 / Fecha de aprobación: 29 de noviembre de 2017 


\section{Resumen}

Con esta obra los grupos de investigación Bacatá y Lenguaje, Identidad y Cultura, conformados por maestros de preescolar, educación Básica, Secundaria, Media y Superior de Bogotá, Colombia, unen sus experiencias frente al estudio de la oralidad en el campo educativo con el fin de contribuir a la comprensión de los procesos de enseñanza y aprendizaje de géneros discursivos orales como la conversación, la asamblea, la exposición oral y un proyecto de evaluación formativa y auténtica de la conversación

Palabras clave

Reseña; prácticas dialógicas; escuela; conversación académica

\section{Abstract}

With this work, the Bacatá and Language, Identity and Culture research groups, made up of preschool, Basic, Secondary, Middle and Higher Education teachers from Bogotá, Colombia, combine their experiences with the study of orality in the educational field in order to to contribute to the un-derstanding of the teaching and learning processes of oral discursive genres such as conversation, assembly, oral presentation and a project of formative and authentic evaluation of the conversation.

Key words

Review; dialogic practices; school; academic conversation 


\section{Introducción}

Cárdenas, M., Torres, A. C., Parra, C. R., P, M E. \& Gutiérrez-Ríos, M. Y. (2017). Prácticas dialógicas en la escuela. Asamblea de aula, exposición oral y conversación académica. Colombia: Red Lenguaje, Red Colombiana para la Transformación de la Formación Docente en Lenguaje.

\begin{abstract}
En el mes de julio del año 2017 fue presentado este libro en el marco del "X Taller de la Red latinoamericana de lenguaje” realizado en México. La obra tuvo gran acogida dentro de la comunidad académica por cuanto abordar un tema que, a pesar de la gran trascendencia que tiene en la escuela, poco se ha asumido con una mirada pedagógico- didáctica.
\end{abstract}

El texto va dirigido a educadores e instituciones escolares interesados en promover el diálogo en las aulas tanto para construir conocimiento colectivamente como para promover la convivencia social y la inclusión.

La obra se desarrolla a través de siete capítulos, en los tres iniciales se ofrecen elementos teóricos relacionados con la oralidad, la investigación, la pedagogía y la didáctica, se plantean los desafíos que los maestros deben enfrentar al trabajar la oralidad en el aula, la forma de desarrollar la competencia comunicativa mediante las prácticas del discurso oral cuya concreción se evidencia en las competencias lingüística, sociolingüística, discursiva, estratégica y cognitiva. En consecuencia, la oralidad es asumida como "una práctica social y cultural cuya naturaleza lingüístico- discursiva implica dos procesos, uno de producción o habla y otro de comprensión, escucha e interpretación”. Estos planteamientos no sólo posibilitan la reflexión de las experiencias pedagógicas que se presentan en capítulos posteriores sino que se van corroborando a lo largo de las reflexiones surgidas de las mismas.
Los cuatro capítulos restantes están dedicados cada uno a presentar una experiencia y las reflexiones pedagógicas que suscita. Así, el capítulo 4 plantea "La asamblea de aula como género discursivo que potencia la oralidad", parte de la necesidad de trabajar esta modalidad discursiva y ofrece unas consideraciones conceptuales referentes a la asamblea como género oral y sus posibilidades para desarrollar las competencias comunicativa y discursiva como también sus propósitos, características y aspectos primordiales.

El capítulo $5^{\circ}$ presenta otra valiosa experiencia "La exposición oral como género discursivo para resignificar la actividad oral del aula”. Este ejercicio tantas veces repetido en nuestras aulas, muchas con grandes deficiencias precisamente porque se realiza de manera espontánea. En esta práctica se escogió el tema, se planeó y desarrollo en grupo, incluidos los padres de familia.

El capítulo 6: "La conversación académica como género discursivo para convivir y comprender nuevos lazos sociales" tiene un valor agregado pues se basa en una práctica realizada con niños que experimentaban barreras en el aprendizaje y en su participación en el aula de clase. Como en las anteriores experiencias se parte de resaltar la necesidad de impulsar la conversación académica no solo para construir conocimiento sino también para tejer convivencia y avanzar en las competencias comunicativa y discursiva. Dentro de las actividades realizadas en esta SD se destacan la creación colectiva del reglamento del grupo, lectura y seguimiento de instrucciones y dialogar para comprender y para escribir textos. 
El capítulo 7 está dedicado a un tema que siempre ha causado gran inquietud y polémica en la escuela, la evaluación, su título: "La evaluación de la conversación académica como proyecto de evaluación formativa y auténtica”, experiencia desarrollada en la Escuela Normal María Montessori de Bogotá con estudiantes de educación media y forma parte de un proyecto más amplio de lectura, escritura y oralidad (LEO).

Entre las consideraciones conceptuales, basadas en la teoría dialógica de Bajtin, se destacan la intención de conversar para aprender como una de las características principales de la conversación académica y la creación de vínculos entre los interlocutores; supone además una formación ideológica y la creación de una conciencia discursiva al potenciar el pensamiento reflexivo y crítico.

Una obra como Prácticas dialógicas en la escuela se convierte en un gran aporte para los maestros que cada día buscan alternativas novedosas para mejorar su trabajo de aula e institucional. Más aún cuando se asume la oralidad como una práctica socio cultural de naturaleza dialógica que posibilita una construcción social, una manera de asumir las relaciones humanas con el fin de formar a los estudiantes para interactuar en la escuela y en su contexto social, bien sea al participar en exposiciones orales, mesas redondas, paneles o en grupos de trabajo, comités, asambleas de vecinos y juntas administrativas, de modo eficaz y constructivo.

Se corrobora que en la escuela, la oralidad formal requiere un trabajo pedagógico didáctico pensado, planeado, realizado y evaluado conjuntamente. Así, el aula se convierte en un espacio dialógico, de interacción continua que le permite al estudiante crear su propia voz para que aprenda a expresar y sustentar sus ideas, sentimientos y propuestas para acceder al saber científico, artístico y cultural; reconocer y respetar al otro y evitar la exclusión. Actitud tan necesaria en la actualidad para interactuar en las redes sociales, una forma de diálogo informal, que debe asumirse con análisis, argumentación sustentada $\mathrm{y}$ sin insultos. En especial en una sociedad que tiene la difícil tarea de construir la tan esquiva la paz y la reconciliación.

En consecuencia, las autoras acuden a los Proyectos de aula y Secuencias didácticas desarrollados en diferentes niveles educativos, desde primaria hasta educación media; configuraciones didácticas que realmente permiten los logros propuestos debido a su carácter participativo, activo y progresivo; experiencias que nos comprueban que trabajar por proyectos no conlleva el desorden y espontaneísmo que algunos suponen. Igualmente se evidencia la transformación en el concepto y las prácticas de evaluación que se asumen en forma compartida, continua y metacognitiva.

Las maestras autoras nos demuestran su saber pedagógico y disciplinar propio de profesionales de la educación que han trajinado durante varios años en las aulas y las instituciones escolares, que han reflexionando su quehacer y estudiado continuamente en forma individual y colectiva, lo que les ha posibilitado hacer propuestas válidas, no desde los escritorios de los tecnócratas o por cumplir con jugosos contratos con el Estado sino a partir de la realidad educativa y social de nuestro país. 